\title{
Selective polyclonal increase of immunoglobulin G1 subclass: a link with Sjögren's syndrome
}

\author{
E M Hay, A J Freemont, R A Kay, R M Bernstein, P J L Holt, R S H Pumphrey
}

\begin{abstract}
A selective polyclonal increase in IgG1 has been described previously in a group of patients with connective tissue disease; nine of the 16 patients had a prior diagnosis of systemic lupus erythematosus (SLE). A detailed clinical and serological study of $\mathbf{3 2}$ patients with this immunoglobulin abnormality has now been made. Most cases showed a characteristic autoantibody profile of antinuclear antibody, rheumatoid factor, and antibodies to Ro and La. Sjögren's syndrome was diagnosed as 'definite' in 16 cases and 'possible' in seven cases by Fox's criteria. The remainder had unclassified connective tissue disease (three), rheumatoid arthritis with dry eyes (two), SLE (one), scleroderma (two), and Raynaud's disease (one). Extraglandular features were invariably present in patients with primary Sjögren's syndrome. The highest concentrations of IgG1 were found in patients with the shortest disease duration. Selective polyclonal increase of IgG1 should alert the doctor to the development of Siögren's syndrome, usually with extraglandular disease and antibodies to Ro and La.
\end{abstract}

Polyclonal hyperglobulinaemia has been reported in association with a variety of connective tissue diseases. We previously described an unusual immunological abnormality in which there was a selective polyclonal increase in IgG1. This occurred almost exclusively in patients with connective tissue disease. A detailed analysis of 32 patients with increased concentrations of IgGl has now been performed and shows in most cases the characteristic serological and clinical picture of Sjögren's syndrome, established or in evolution.

University Department of Rheumatology, Infirmary, Oxford Road, Manchester M13 9WL E M Hay

A J Freemont

R M Bernstein

P J L Holt

Regional Immunology Service, St Mary's Hospital, Hathersage Road, Manchester M13 0JH

R A Kay

R S H Pumphrey

Correspondence to:

Dr Hay.

Accepted for publication

20 July 1989

\section{Patients and methods} PATIENTS

A computerised filing system was used to screen approximately 1000 patients in whom IgG subclasses had been estimated between 1983 and $1988 .{ }^{2}$ Thirty two patients with a selective polyclonal increase in the concentration of IgG1 were identified in this way and 26 were reviewed in the outpatient clinic by a single doctor; two patients had died and four were unavailable for review. As a comparison group all patients with antibodies to extractable nuclear antigens in whom IgG subclasses had been measured were recorded.

\section{CLINICAL ASSESSMENT}

The clinical history and physical examination were recorded on a proforma, with particular attention to features of connective tissue disease. The duration of disease was estimated from the history and review of the case notes.

INVESTIGATIONS FOR EXOCRINE SICCA SYNDROME Schirmer's test of tear secretion was conducted in all patients; it was considered positive if less than $9 \mathrm{~mm}$ of the standard test paper was wet after five minutes. ${ }^{3}$

Salivary gland involvement was assessed by minor gland biopsy or salivary gland scintigraphy, or both, in 26 patients. Lower lip biopsy was performed on 19 patients and the specimen fixed in formal-saline and processed in the routine manner. Sections stained with haematoxylin and eosin were reported 'blind' by one pathologist (AJF). The tissue was scored in accordance with the method of Tarpley et al. ${ }^{4}$

Parotid and submandibular gland function was assessed in eight patients by sequential salivary gland scintigraphy, visualising the uptake, concentration, and excretion of ${ }^{99 \mathrm{~m}} \mathrm{Tc}$ pertechnetate with a gamma scintillation camera. Control images were obtained in patients having routine ${ }^{99 \mathrm{~m}} \mathrm{Tc}$ pertechnetate scans for visualisation of the thyroid gland (autoimmune thyroid disease excluded). ${ }^{5}$

\section{CLASSIFICATION OF SJÖGREN'S SYNDROME}

'Definite' Sjögren's syndrome was diagnosed in agreement with the criteria proposed by Fox et $a l^{3}$ and required the presence of four features: positive Schirmer's test, symptomatic xerostomia, minor salivary gland biopsy scoring $>2$ on the Tarpley scale, and serological evidence of systemic autoimmune disease. ${ }^{4}$ In those of our patients refusing a lip biopsy an isotope salivary gland scan was substituted. Patients fulfilling only three criteria were defined as 'possible' Sjögren's syndrome and patients with all four criteria in the presence of another recognised connective tissue disease were considered to have secondary Sjögren's syndrome. Patients with erosive rheumatoid arthritis and positive Schirmer's test were defined as rheumatoid arthritis/dry eyes.

\section{EXTRAGLANDULAR DISEASE}

In primary Sjögren's syndrome extraglandular disease was defined as the presence of at least one of the following clinical findings: renal disease with proteinuria $>500 \mathrm{mg}$ in 24 hours, serum creatinine $>135 \mu \mathrm{mol} / \mathrm{l}$, renal tubular acidosis, interstitial nephritis, systemic or 
cutaneous vasculitis, Raynaud's phenomenon, splenomegaly, lymphadenopathy, or pulmonary involvement shown by chest $x$ ray or pulmonary function tests. ${ }^{6}$

\section{LABORATORY ASSESSMENT}

Blood was taken for estimation of haemoglobin, differential and total white cell count and platelets, serum creatinine, urea, electrolytes, and liver function tests, using standard autoanalyser techniques. Serum protein electrophoresis was performed using the Hiphore kit (Gelman Sciences, UK). Concentrations of IgG, $\operatorname{IgA}$, and IgM were measured by rate nephelometry (Beckman RIIC Ltd, US). The IgG subclasses IgG1, IgG2, and IgG3 were measured by radial immunodiffusion. ${ }^{1}$ IgG4 concentrations were measured by a competitive inhibition enzyme linked immunosorbent assay (ELISA) technique. ${ }^{7}$ Antinuclear antibody was detected by indirect immunofluorescence using $\mathrm{HEp}_{2}$ cells as substrate. ${ }^{8}$ Antibodies to soluble cellular antigens were detected by counterimmunoelectrophoresis. ${ }^{9}$ IgM rheumatoid factor levels were measured with two commercial kits: RAHA (Fujirebio, Japan) and latex (Wellcome Diagnostics, UK). Antibodies to dsDNA and cardiolipin were measured by an ELISA. ${ }^{1011}$

\section{STATISTICS}

Kendall's rank correlation coefficient, MannWhitney's U test, and a two tailed Student's $t$ test were used where appropriate.

\section{Results}

\section{IMMUNOGLOBULIN VALUES}

The immunoglobulin values indicated in fig 1 show hypergammaglobulinaemia present in all 32 patients identified for the study. The range of total IgG was $16 \cdot 5-62$ g/l. The IgGl subclass was raised in all cases with a range of $14-62 \mathrm{~g} / \mathrm{l}$. Indeed, the concentration of IgG1 was $>30 \mathrm{~g} / \mathrm{l}$ in 13 patients. By contrast, the concentration of IgG2 was subnormal in 12 cases and at the lower end of the normal range in the remainder.

Figure 1: Immunoglobulin subclass values in the 32 patients with a selective polyclonal increase in IgGI. Rectangular boxes represent the normal range.

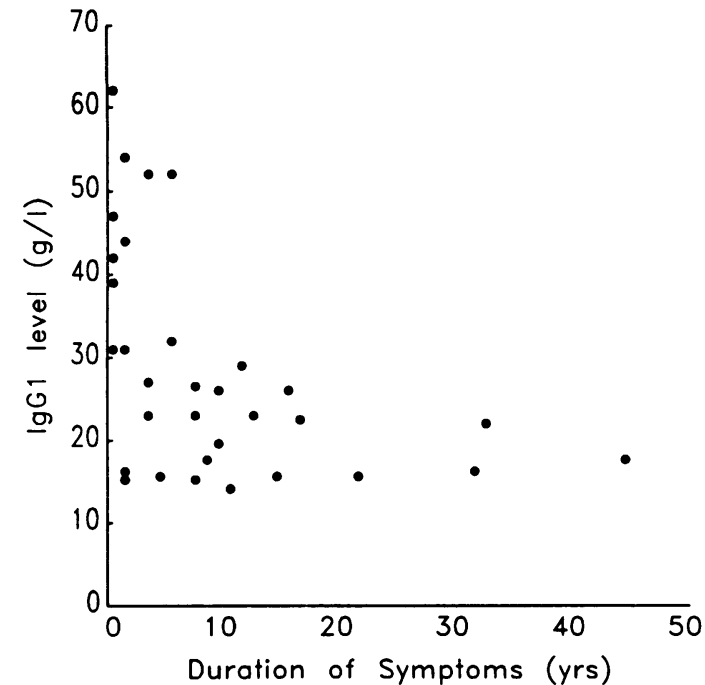

Figure 2: Correlation between concentration of IgGI and disease duration. $\tau=0 \cdot 39, p<0 \cdot 002$.

Values for IgG3 and IgG4 fell mainly within the reference range. Concentrations of $\operatorname{IgA}$ were raised in seven cases and of IgM in four cases. No monoclonal bands were found on serum protein electrophoresis. IgGl concentrations were highest in early disease; there was an inverse relation between IgG1 concentration and disease duration $(\tau=0.39, \mathrm{p}<0.002 ;$ fig 2$)$. Immunoglobulin values were measured serially for five years in 24 patients. Increased IgGl was a constant finding, except for three patients treated with azathioprine and prednisolone for associated connective tissue disease, in whom concentrations returned to normal. In all three the IgG1 rose again when immunosuppression was discontinued. Treatment with low dose prednisolone or chloroquine phosphate did not affect the immunoglobulin concentrations.

\section{AUTOANTIBODY PROFILE}

Table 1 shows the autoantibody profiles in these patients. Antinuclear antibodies were present in $28(87 \%)$ patients and antibodies to soluble cellular antigens were detected in 27 . Of the latter, antibodies to both $\mathrm{Ro}$ and $\mathrm{La}$ were present in 24 cases, to Ro alone in one, to Ul(RNP) in one, and to Jo-1 (together with Ro and La) in one case. Only one patient had significant titres of anti-dsDNA and none had anticardiolipin antibodies. High titres of rheumatoid factor were present in $26(81 \%)$ patients. Only in one patient was no evidence of autoantibody production detected. To set these antibody prevalences in perspective, a selective increase of IgG1 was found in $33 / 42$ patients with antibodies to Ro and La, but in only $8 / 42$ with Ro alone, 1/23 with anti-RNP, and 1/4 with anti-Jo-l (this patient also having antibodies to Ro and La). The mean IgGl concentration was significantly higher in the patients with antibodies to both Ro and La antigen than in those with antibody to Ro alone (22 $\mathrm{g} / \mathrm{l} v$ $10.8 \mathrm{~g} / \mathrm{l}, \mathrm{p}<0.001$ ).

ACUTE PHASE RESPONSE

The erythrocyte sedimentation rate was increased 
Table 1: Autoantibody profile of 32 patients with selective increase of IgGI

\begin{tabular}{|c|c|c|c|c|c|}
\hline & $\begin{array}{l}\text { Definite } S S^{*} \\
(n=16)\end{array}$ & $\begin{array}{l}\text { Possible } S S \\
(n=7)\end{array}$ & $\begin{array}{l}R A^{*} / d r y \text { eyes } \\
(n=2)\end{array}$ & $\begin{array}{l}\text { Others } \\
(n=7)\end{array}$ & $\begin{array}{l}\text { Total } \\
(n=32)\end{array}$ \\
\hline $\begin{array}{l}\text { ANA* } \\
\text { Anti-Ro and La } \\
\text { Anti-Ro } \\
\text { Anti-RNP } \\
\text { Anti-Jo-l† } \\
\text { RF* } \\
\text { Anti-dsDNA } \\
\text { Anticardiolipin }\end{array}$ & $\begin{array}{r}15 \\
14 \\
1 \\
1 \\
13 \\
1 \\
-\end{array}$ & $\begin{array}{l}7 \\
6 \\
1 \\
- \\
-6 \\
-\end{array}$ & $\begin{array}{l}- \\
z \\
\frac{2}{z} \\
-\end{array}$ & $\begin{array}{l}6 \\
\frac{4}{-} \\
\frac{5}{-} \\
-\end{array}$ & $\begin{array}{r}28 \\
24 \\
1 \\
1 \\
1 \\
26 \\
1 \\
-\end{array}$ \\
\hline
\end{tabular}

*SS=Sjögren's syndrome; RA=rheumatoid arthritis; ANA=antinuclear antibodies; $\mathbf{R F}=$ rheumatoid factor.

†Also with anti-Ro and anti-La.

$\ddagger R F=$ sheep cell agglutination test $>64$, latex test $>32$.

to $>30 \mathrm{~mm}$ in the first hour in $72 \%$ of cases at some stage of follow up, yet the $\mathrm{C}$ reactive protein remained normal in all but three patients who proved to have erosive arthritis of rheumatoid type.

\section{HAEMATOLOGICAL INDICES}

Leucopenia, with a total white cell count $<3.0 \times 10^{9} / 1$ on more than two occasions, was recorded in seven cases. Another patient had transient thrombocytopenia and one more had an episode of life threatening pancytopenia requiring transfusion of blood products.

RENAL FUNCTION

Serum bicarbonate was low in three patients

Table 2: Prior diagnoses in patients with raised IgGI

\begin{tabular}{lr}
\hline Systemic lupus erythematosus & 18 \\
Rheumatoid arthritis & 7 \\
Mixed connective tissue disease & 1 \\
Siögren's syndrome & 1 \\
Dermatomyositis & 1 \\
Raynaud's disease & 1 \\
Undiagnosed & 3 \\
Total & 32 \\
\hline
\end{tabular}

Table 3: Assigned diagnoses in patients with raised IgGI

\begin{tabular}{lc}
\hline 'Definite' Sjögren's syndrome & 16 \\
Primary 8 & \\
Secondary* 8 & 7 \\
'Possible' Sjögren's syndrome & 2 \\
RA/dry eyes & 3 \\
Unclassified connective tissue disease & 1 \\
Systemic lupus erythematosus & 2 \\
Scleroderma & 1 \\
Raynaud's disease & 32 \\
Total & \\
\hline
\end{tabular}

* Secondary Siögren's syndrome: systemic lupus erythematosus (three); mixed connective tissue disease (one); primary biliary cirrhosis (one); dermatomyositis (two); rheumatoid arthritis (one). with values of $16-20 \mathrm{mmol} / \mathrm{l}$. Urine $\mathrm{pH}>5$ suggested a renal tubular defect of acid excretion. No patient had significant proteinuria or reduction of creatinine clearance. Renal biopsy was not performed.

\section{DIAGNOSIS}

Table 2 gives details of the previous working diagnoses obtained from the case notes of the 32 patients (29 female) aged 47 years (range 29-75). Twenty six patients were examined afresh, two had died, and four were unavailable for review. Schirmer's test was positive in 21 cases and 23 patients had symptomatic xerostomia. Histological examination of a minor salivary gland scored $>2$ on the Tarpley scale in 14 of 19 patients biopsied. The biopsy was reported as normal in one patient and in four the specimens were inadequate. $\mathrm{A}^{99 \mathrm{~m}} \mathrm{Tc}$ pertechnetate isotope scan of the salivary glands in eight patients confirmed parotid and submandibular gland dysfunction in five, was equivocal in one, and normal in two. A minor salivary gland biopsy was performed in the patient with the equivocal scan and showed changes consistent with Sjögren's syndrome. Recurrent parotid swelling was recorded in five patients. Thus 19 patients had evidence of salivary gland involvement.

On the basis of these findings the original diagnoses were revised (table 3). Definite Sjögren's syndrome was present in 16 patients, possible Sjögren's syndrome in seven, and a further two patients had keratoconjunctivitis sicca and rheumatoid arthritis. Of the remaining seven patients, three had an unclassified connective tissue disease, two had systemic sclerosis, one had systemic lupus erythematosus (SLE), and one Raynaud's disease. Assessment of sicca systems was incomplete in eight patients because of death, lack of consent, or unavailability for review: three patients with possible Sjögren's syndrome (two with positive Schirmer's tests), all three patients with unclassified connective tissue disease (one with positive Schirmer's test), and both patients with rheumatoid arthritis and dry eyes.

Disease duration was shorter in those with possible than in those with definite Sjögren's syndrome (mean five years $v 13$ years (NS)).

ASSOCIATED CLINICAL FEATURES (table 4).

Arthritis was present in 21 patients. Radiological evidence of erosions was present in only three

Table 4: Clinical features in 32 patients with selective increase of $I g G I$

\begin{tabular}{|c|c|c|c|c|c|c|}
\hline & $\begin{array}{l}\text { Definite } S S^{*} \\
(n=16)\end{array}$ & $\begin{array}{l}\text { Possible SS } \\
(n=7)\end{array}$ & $\begin{array}{l}\text { Unclassified } C T D^{*} \\
(n=3)\end{array}$ & $\begin{array}{l}R A^{*} / d r y \text { eyes } \\
(n=2)\end{array}$ & $\begin{array}{l}\text { Others } \\
(n=4)\end{array}$ & $\begin{array}{l}\text { Total } \\
(n=32)\end{array}$ \\
\hline $\begin{array}{l}\text { Cutaneous manifestations } \\
\text { Raynaud's syndrome } \\
\text { Arthritis } \\
\text { Parotid swelling } \\
\text { Neuropsychiatric } \\
\text { Migraine } \\
\text { Serositis } \\
\text { Alopecia } \\
\text { Myositis } \\
\text { Renal tubular acidosis } \\
\text { Primary biliary cirrhosis } \\
\text { Pulmonary fibrosis } \\
\text { Thyroid disease }\end{array}$ & $\begin{array}{r}16 \\
8 \\
8 \\
5 \\
5 \\
2 \\
1 \\
1 \\
2 \\
3 \\
1 \\
2 \\
2\end{array}$ & $\begin{array}{l}7 \\
5 \\
= \\
= \\
= \\
= \\
= \\
\overline{1}\end{array}$ & $\begin{array}{l}3 \\
2 \\
3 \\
- \\
= \\
-1 \\
= \\
= \\
1\end{array}$ & $\begin{array}{l}\bar{z} \\
= \\
= \\
= \\
= \\
= \\
=\end{array}$ & $\begin{array}{l}\overline{2} \\
3 \\
\overline{-} \\
1 \\
1 \\
= \\
\overline{-} \\
1\end{array}$ & $\begin{array}{r}23 \\
18 \\
21 \\
5 \\
5 \\
4 \\
2 \\
3 \\
2 \\
3 \\
1 \\
2 \\
5\end{array}$ \\
\hline
\end{tabular}

${ }^{*} \mathrm{SS}=$ Siögren's syndrome; $\mathrm{CTD}=$ connective tissue disease; $\mathrm{RA}=$ rheumatoid arthritis. 
and 16 had a mild inflammatory polyarthropathy, often palindromic in nature. Two patients had tenosynovitis of the hands with Jaccoud's deformity. Raynaud's phenomenon was present in 18 patients. Cutaneous manifestations included photosensitivity in seven, angioneurotioedema in two, discoid lupus erythematosus in two, subacute cutaneous lupus erythematosus in two, and a purpuric vasculitic rash of the lower legs in four patients. Dermatomyositis was present in two patients. Neuropsychiatric symptoms were seen in nine patients: migraine in four, grand mal epilepsy in two, trigeminal neuralgia in one, severe depression requiring admission to hospital in three, and acute confusional state leading to coma and death in one case. There was autoimmune thyroid disease in five: hypothyroidism in three, thyrotoxicosis in two.

\section{Discussion}

This report concerns 32 patients with a discrete immunological abnormality characterised by a selective polyclonal increase in IgGl. All had features of a connective tissue disease and most had antinuclear antibody, rheumatoid factor, and antibodies to Ro and La. The IgGl concentrations found often exceeded those seen in multiple myeloma, but no patient had a monoclonal band on serum protein electrophoresis. Moutsopoulos et al reported a monoclonal band in the urine of a minority of cases with Sjögren's syndrome, ${ }^{12}$ but we have not repeated this work. The highest concentrations of IgGl were found early in the disease: there was an inverse relation between IgGl concentration and disease duration.

As might be expected from the profile of autoantibodies, Sjögren's syndrome was the predominant diagnosis, being definite in 16 patients and possible in seven; two patients had rheumatoid arthritis with dry eyes. A further three patients with unclassified connective tissue disease were serologically indistinguishable from those with definite Sjögren's syndrome. The duration of disease was shorter in patients with possible Sjögren's syndrome than in the group as a whole, and we presume that they are in a prodromal phase of the disease. Of the remaining four patients, two had systemic sclerosis, one had SLE, and one Raynaud's disease. Our investigations for Sjögren's syndrome were incomplete in eight cases because of death, unavailability for review, or lack of consent. These patients account for three of those with possible Sjögren's syndrome, all three with unclassified connective tissue disease, and the two with dry eyes and rheumatoid arthritis. We may, therefore, still be underestimating the true incidence of Sjögren's syndrome in our study.

In the patients with Sjögren's syndrome, all selected for high IgG1, antibodies to Ro and La were present in $82 \%$. Anti-Ro has been associated with hyperglobulinaemia and the presence of systemic complications in Sjögren's syndrome, ${ }^{13}$ but it is the prevalence of anti-La that is exceptional in our study. Furthermore, when we reviewed the IgG subclasses of patients in whom positive antibodies to extractable nuclear antigen had been recorded, a selective increase of IgG1 was present in 33 of 42 with both antiRo and anti-La, but only eight of 42 with antiRo alone. The mean IgGl was highest in the group with antibodies to both $\mathrm{Ro}$ and $\mathrm{La}$, suggesting an association between high IgGl and anti-La in Sjögren's syndrome.

Included in this study are all 24 patients attending our department with autoantibodies to Ro and La. Sjögren's syndrome was definite in 15 cases and possible in seven (three of these refused full investigation). The two remaining cases had SLE with negative Schirmer's test, but had refused lip biopsy. There has been debate for many years ${ }^{14} 15$ as to the significance of antibodies to Ro and $\mathrm{La}$ and their association with SLE or Sjögren's syndrome. Our results suggest that all patients with antibodies to both Ro and La have Sjögren's syndrome, either established or in a prodromal phase.

There was a plethora of extraglandular features in the patients with Sjögren's syndrome. In eight patients the associated clinical features were sufficient to fulfil the diagnostic criteria for another connective tissue disease and these were classified as secondary Sjögren's syndrome. ${ }^{16}$ The distinction between primary Sjögren's syndrome and SLE/Sjögren's syndrome overlap may be artificial, however, as the two groups did not differ over the range of serological tests performed. On the other hand, the neuropsychiatric complications in $20 \%$ of our cases with Sjögren's syndrome were confined to those with SLE/Sjögren's syndrome or mixed connective tissue disease/Sjögren's syndrome overlap and did not occur in primary Sjögren's syndrome. This is contrary to the experience of Alexander $e t a l^{13}$ and may in part reflect differing classification of cases or a selection bias in patients attending a tertiary referral centre in the United States. The absence of antibodies to DNA or cardiolipin in our patients with central nervous system involvement is noteworthy.

The prior diagnoses in this study emphasise how easy it is to underestimate the prevalence of Sjögren's syndrome. ${ }^{17}$ Correct diagnosis of Sjögren's syndrome may offer reassurance that an erosive arthritis is unlikely to develop and treatment with gold, penicillamine, or sulphasalazine is inappropriate. The question does arise whether the finding of a high concentration of IgGl should be an indication for immunosuppression in an attempt to avert irreversible damage to exocrine glands. The present diagnostic criteria for Sjögren's syndrome recognise only established disease and miss the prodromal phase when treatment might limit eventual glandular damage. Measurement of IgGl (and future quantitative assays for anti-La) may enable much earlier diagnosis and treatment and give a guide to disease activity. For the present, a selective increase in the concentration of IgGl suggests a diagnosis of Sjögren's syndrome, usually with extraglandular disease and autoantibodies to Ro and La.

I Kay R A, Wood K J, Bernstein R M, Holt P J L, Pumphrey $R$ S H. An IgG subclass imbalance in connective tissue R S H. An IgG subclass imbalance in con
disease. Ann Rheum Dis 1988; 47: 536-41. 
2 Pumphrey R S H. Automated filing and reporting in a regional immunology service laboratory using a PET computer. Med Inf (Lond) 1981; 6: 279-83.

3 Fox R I, Robinson C, Curd J, Michelson P, Bone R, Howell F V. First international symposium on Sjögren's syndrome: suggested criteria for classification. Scand $\mathcal{f}$ Rheumatol [Suppl] 1986; 61: 28-30.

4 Tarpley T M, Anderson L G, White C L. Minor salivary gland involvement in Siögren's syndrome. Oral Surg Oral Med Oral Pathol 1974; 37: 64-74.

5 Schall G L, Anderson L G, Wolf R O, et al. Xerostomia in Sjögren's syndrome: evaluation by sequential salivary scintigraphy. FAMA 1971; 216: 2109-16.

6 Manoussakia M N, Tzioufas A G, Pange P J E, Moutsopoulo $H$ M. Serological profiles in groups of patients with Siögren's syndrome. Scand f Rheumatol [Suppl] 1986; 61: $89-92$.

7 Wilson P B, Wood K J, Doré P, Swainson J A, Brenchley P E, Pumphrey R S. Investigation of IgG4 levels in atopic patients using a competitive inhibition assay employing biotinylated IgG4 myeloma and avidin peroxidase. f Immunol Methods 1986; 87: 59-67.

8 Bernstein R M, Steigerwald J C, Tan E M. Association of antinuclear and antinucleolar antibodies in progressive systemic sclerosis. Clin Exp Immunol 1982; 48: 43-51.

9 Bernstein R M, Bunn C C, Hughes G R V. Identification of antibodies to acidic antigens by counterimmunoelectrophoresis. Ann Rheum Dis 1982; 41: 554-5.
10 Klotz J L, Minami R M, Teplitz R L. An enzyme linked immunosorbent assay for antibodies to native and denatured DNA. F Immunol Methods 1979; 29: 155-65.

11 Snowden N, Wilson P, Pumphrey R S. Anticardiolipin antibodies in systemic lupus erythematosus. Ann Rheum Dis 1989; 48: 80-6.

12 Moutsopoulos H M, Costello R, Drosos A A, Mavridis A K, Papadopoulos N M. Demonstration and identification of monoclonal proteins in the urine of patients with Sjögren's syndrome. Ann Rheum Dis 1985; 44: 109-12.

13 Alexander E L, Arnett F C, Provost T T, Stevens M B Siögren's syndrome: association of anti-Ro(SS-A) antibodies with vasculitis, haematologic abnormalities and serological hyperreactivity. Ann Rheum Dis 1983; 42: 155-9.

14 Tan E M, Chan E K, Sullivan K F, Rubin R L. Antinuclear antibodies (ANAs): diagnostically specific immune markers and clues towards the understanding of systemic autoimmunity. Clin Immunol Immunopathol 1988; 47: 121-41.

15 Hughes G. Autoantibodies in lupus and its variants: experience in 1000 patients. $\mathrm{Br} \mathrm{Med} 7$ 1984; 289: 339-42.

16 Tan E M, Cohen A S, Fries J F, et al. The 1982 revised criteria for the classification of SLE. Arthritis Rheum 1982. 25: 1271-7.

17 Venables $P$. Sjögren's syndrome: differential diagnosis immunopathology and genetics. $A R C$ reports on rheumatic diseases (Series 2). London: Arthritis and Rheumatism Council, 1988: No 10. 